\title{
SMG1 and NIK regulate apoptosis induced by Smac mimetic compounds
}

\author{
HH Cheung ${ }^{*, 1}$, M St. Jean ${ }^{1}$, ST Beug ${ }^{1}$, R Lejmi-Mrad ${ }^{1,2}$, E LaCasse $^{1}$, SD Baird ${ }^{1}$, DF Stojdl ${ }^{1,3}$, RA Screaton ${ }^{1,2}$ and RG Korneluk ${ }^{*, 1,2,3}$
}

Smac mimetic compounds (SMCs) are experimental small molecules that induce tumour necrosis factor alpha (TNF $\alpha$ )-dependent cancer cell death by targeting the inhibitor of apoptosis proteins. However, many cancer cell lines are resistant to SMC-mediated apoptosis despite the presence of TNF $\alpha$. To add insight into the mechanism of SMC-resistance, we used functional siRNA-based kinomic and focused chemical screens and identified suppressor of morphogenesis in genitalia-1 (SMG1) and NF- $\kappa$ B-inducing kinase (NIK) as novel protective factors. Both SMG1 and NIK prevent SMC-mediated apoptosis likely by maintaining FLICE inhibitory protein (c-FLIP) levels to suppress caspase-8 activation. In SMC-resistant cells, the accumulation of NIK upon SMC treatment enhanced the activity of both the classical and alternative nuclear factor- $\kappa B$ pathways, and increased $c$-FLIP mRNA levels. In parallel, persistent SMG1 expression in SMC-resistant cells repressed SMC-mediated TNF $\alpha$-induced JNK activation and c-FLIP levels were sustained. Importantly, SMC-resistance is overcome by depleting NIK and SMG1, which appear to facilitate the downregulation of c-FLIP in response to SMC and TNF $\alpha$ treatment, leading to caspase-8-dependent apoptosis. Collectively, these data show that SMG1 and NIK function as critical repressors of SMC-mediated apoptosis by potentially converging on the regulation of C-FLIP metabolism.

Cell Death and Disease (2011) 2, e146; doi:10.1038/cddis.2011.25; published online 14 April 2011

Subject Category: Cancer

The inhibitor of apoptosis (IAP) proteins are key repressors of programmed cell death. Evasion from apoptosis is a hallmark of tumourigenesis, ${ }^{1}$ and consequently, the IAPs have become important targets for the development of anticancer therapies. ${ }^{2}$ Current approaches that are under clinical development for the targeting of the IAPs include antisense oligonucleotides that repress IAP gene expression and synthetic small molecules that antagonize IAP function. ${ }^{3}$

The suppression of apoptosis by the IAPs is primarily mediated through the inhibition of caspase activity, either directly via their baculoviral IAP repeat (BIR) domains or indirectly through their ubiquitin E3 ligase RING domain. The ability of the BIR2 domain of X-linked IAP (XIAP) to bind and inhibit the effector caspases-3 and -7 , and the ability of the BIR3 domain of XIAP to function as a direct inhibitor for the initiator caspase-9, have been extensively documented. ${ }^{4,5}$ As well, recent evidence indicates that the ubiquitin E3 ligase RING domain of cellular IAP1 (cIAP1) and cellular IAP2 (clAP2) can indirectly inhibit apoptosis by modulating the ubiquitination status of the kinase receptor-interacting protein 1 (RIP1). ${ }^{6-8}$ In response to tumour necrosis factor alpha (TNF $\alpha$ ), clAP1 or clAP2 facilitates the ubiquitination of RIP1 and thereby blocks the recruitment of caspase- 8 and FADD to RIP1, preventing the formation of the death-inducing complex II. ${ }^{9,10}$ The indirect inhibition of caspase- 8 by clAP1 and clAP2 is indispensable for the prevention of TNF $\alpha$ mediated apoptosis.

Smac mimetic compounds (SMCs) are small molecule therapeutics that target the IAPs and are currently in clinical trials for cancer. ${ }^{3}$ The structure of SMCs were rationally designed from a conserved IAP-binding motif that contains the AVPI tetrapeptide amino terminal sequence of Smac, which binds to the BIR2 and BIR3 domains of CIAP1, CIAP2 and XIAP. ${ }^{11-13}$ The mode of action for SMCs in sensitive cancer cells involves the rapid activation of the ubiquitin E3 ligase of ClAP1 and ClAP2, leading to autoubiquitination and proteasomal degradation of these clAPs., ${ }^{6,17}$ In the absence of the clAPs, RIP1 ubiquitination is markedly reduced, ${ }^{6-8}$ thereby sensitizing cancer cells to TNF $\alpha$ mediated apoptosis via the preferential formation of the death-inducing complex II.

Resistance to SMC treatment has been shown in diverse cancer cell lines ${ }^{9,18}$ and in a xenograft model. ${ }^{18}$ The concomitant treatment of SMC and TNF $\alpha$ can reverse the resistance in some cancer cell lines to SMC treatment alone; however, about half of the cell lines surveyed remain resistant to SMC treatment despite the addition of exogenous TNF $\alpha .{ }^{9}$ This resistance may limit the impact of SMCs in the clinic despite the abundance of TNF $\alpha$ in the tumour microenvironment. ${ }^{19}$ Therefore, identifying the basis for

\footnotetext{
${ }^{1}$ Apoptosis Research Centre, Children's Hospital of Eastern Ontario Research Institute, Ottawa, Ontario K1H 8L1, Canada; ${ }^{2}$ Department of Cellular and Molecular Medicine, University of Ottawa, Ottawa, Ontario K1H 8M5, Canada and ${ }^{3}$ Department of Biochemistry, Microbiology and Immunology, University of Ottawa, Ottawa, Ontario K1H 8M5, Canada

*Corresponding author: HH Cheung or RG Korneluk, Apoptosis Research Centre, Children's Hospital of Eastern Ontario, Research Institute, 401 Smyth Road, Ottawa, Ontario K1H 8L1, Canada. Tel: 6137383927 (HH Cheung)/613 7383281 (RG Korneluk); Fax: 613738 4833; E-mail: herman@arc.cheo.ca or bob@arc.cheo.ca Keywords: cancer; Smac mimetic compound; TNF $\alpha$; kinomic screen; c-FLIP

Abbreviations: BIR, baculoviral IAP repeat; c-FLIP, FLICE inhibitory protein; cIAP, cellular IAP; FITC, fluorescein isothiocyanate; IAP, inhibitor of apoptosis; NF- $\kappa$ B, nuclear factor- $\kappa \mathrm{B}$; NIK, NF- $\kappa$ B-inducing kinase; NSCLC, non-small cell lung carcinoma; RIP1, receptor-interacting protein 1; SMC, Smac mimetic compounds; SMG1, suppressor of morphogenesis in genitalia-1; TNF $\alpha$, tumour necrosis factor alpha; XIAP, $x$-linked IAP

Received 08.10.10; revised 23.2.11; accepted 01.3.11; Edited by P Salomoni
} 
SMC-resistance will benefit the application of SMCs as a cancer therapy by allowing for the rational development of treatment strategies.

To gain insight into the mechanism of SMC-resistance in cancer cells, we undertook functional siRNA-based kinomic screens and identified targets that sensitize cancer cells to the SMCs AEG40730 and SM-164. On the basis of resistance to cell death in response to SMC and $\mathrm{TNF}_{\alpha}$ treatment, ${ }^{9}$ we selected the non-small cell lung carcinoma (NSCLC) cell line $\mathrm{H} 226$ for the investigation of pro-survival kinases. Interestingly, we identified NF- $\kappa$ B-inducing kinase (NIK) as a prosurvival kinase. This pro-survival property differs from the previously suggested role of NIK as a pro-death regulator functioning to promote the production of TNF $\alpha .{ }^{16,17}$ Furthermore, a siRNA screen that simultaneously targeted NIK in combination with the kinome revealed that the additional loss of suppressor of morphogenesis in genitalia-1 (SMG1) synergized with NIK knockdown to cause apoptosis upon SMC and TNF $\alpha$ co-treatment. We further propose that SMG1 and NIK are regulators for the metabolism of FLICE inhibitory protein (c-FLIP), a caspase-8 inhibitor. Our results show that SMG1 and NIK act as important repressors of SMC-mediated cell death possibly by sustaining the expression of c-FLIP.

\section{Results}

Functional siRNA kinome screens identified NIK and SMG1 as protective factors for SMC-mediated TNF $\alpha$ induced cell death. To explore factors underlying the resistance of cancer cells to SMC-mediated TNF $\alpha$-induced cell death, we performed a synthetic lethal screen in which 691 kinome targets were individually knocked down before the co-treatment of SMC (AEG40730) and TNF $\alpha$. To determine the effects of each knockdown on cell viability in response to the drugs, we used Alamar Blue, which measures the activity of the mitochondrial respiratory chain. ${ }^{20}$ We previously reported that the NSCLC H226 is a SMC-resistant cell line that has an intact apoptotic pathway and the resistance of $\mathrm{H} 226$ cells to SMC-mediated TNF $\alpha$ induced cell death is reversed by c-FLIP silencing. ${ }^{9}$ The dependency on c-FLIP allows us to assess the robustness of the assay by comparing SMC and TNF $\alpha$ sensitivity of $\mathrm{H} 226$ cells treated with c-FLIP siRNA to non-targeting siRNA. The assay offered a wide dynamic range and negligible data variability, resulting in a Z-factor of 0.59 (Figure 1a), indicating that the kinome screen is a suitable assay for identifying bona fide hits. ${ }^{21}$ The efficiency of siRNA targeting c-FLIP was confirmed by immunoblotting (Figure 1b). The siRNA kinomic library screen identified CKS2, AKT2, KHK, IKBKB, SMG1 and PIM2 as potential protective factors in SMC-mediated TNF $\alpha$-induced cell death (Figure 1c). Interestingly, the synthetic lethal kinomic screen also identified MAP3K14, which encodes for the protein NIK, as the strongest suppressor in the library (Figure 1c).

NIK has been hinted as a component for the execution of SMC-mediated cell death, ${ }^{16,17}$ but here, we identify NIK as a repressor of SMC-mediated cell death. The potential duality of NIK function to inhibit or promote SMC-mediated cell death suggests that NIK function is dependent on the specific cellular context. To investigate the contribution of additional genes that might synergize with NIK-depletion in SMCmediated TNF $\alpha$-induced cell death, we screened the kinomic siRNA library with NIK-depleted H226 cells. We identified NEK9, RPS6KA3, LYN, SMG1 and STK38L as genes that potentially represent secondary blocks of SMC-mediated TNF $\alpha$-induced cell death in NIK-depleted H226 cells (Figure 1d).

To determine which candidates from the NIK siRNAcoupled secondary screen were most relevant in SMCmediated cell death, we assessed protein levels of the new candidates in MDA-MB-231 cells in response to SMC treatment. The MDA-MB-231 breast carcinoma cell line responds robustly to SMC treatment (Figure 1e) in a manner dependent on the production of $\mathrm{TNF} \alpha,{ }^{16}$ with an $\mathrm{IC}_{50}$ of $1.32 \mathrm{nM}$ by SMC-AEG40730. ${ }^{9}$ In the presence of SMC, we found that NEK9, RPS6KA3, LYN, SMG1 and STK38L maintained their protein expression levels, but SMG1 was downregulated (Figure 1f). The loss of cIAP1, cIAP2 and XIAP by SMC treatment was also confirmed (Figure 1f).

Since the loss of SMG1 coincides with the onset of SMCmediated cell death in MDA-MB-231 cells (Figures 1e and f), we reasoned that SMG1 is likely to be a mechanistically relevant protective factor against SMC treatment. We used siRNAs from an alternative source to confirm that the dual silencing of SMG1 and NIK is more effective than single SMG1 or NIK knockdown to sensitizing H226 cells to SMCmediated TNF $\alpha$-induced cell death (Figure 2a). We next extended our assessment to NSCLC H460 and H661, which are among the most resistant cell lines to SMC treatment. ${ }^{9}$ Similar to H226 cells, combined knockdown of NIK and SMG1 decreased viability of $\mathrm{H} 460$ and $\mathrm{H} 661$ cells that were treated with SMC and TNF $\alpha$ (Figure 2a). SMG1 knockdown alone also sensitized $\mathrm{H} 460$ and $\mathrm{H} 661$ cells to SMC and TNF $\alpha$ treatment, while the effect of NIK knockdown was more modest (Figure 2a).

To assess the specificity of sensitization in SMG1 and NIKdepleted cells, we analyzed the effect of SMG1 and NIK knockdown with respect to cell death caused by other apoptotic triggers, such as VP16, staurosporine and cycloheximide in combination with TNF $\alpha$. We found that combined SMG1 and NIK knockdown has no effects on VP16- and staurosporine-induced cell death, but sensitizes cell death triggered by cycloheximide and TNF $\alpha$ treatment (Supplementary Figure 1). Sensitization of SMG1- and NIK-depleted cells to cycloheximide and TNF $\alpha$ treatment may in part be due to IAP downregulation by cycloheximide treatment. ${ }^{22-24}$ Overall, these results suggest that NIK and SMG1 are relatively specific suppressors of SMC-mediated TNF $\alpha$-induced cell death.

Depletion of SMG1 and NIK promotes SMC-mediated TNF $\alpha$-induced caspase-8 activation. To determine the underlying mechanism of cell death in SMG1- and NIKdepleted cells, we assessed for caspase activity in response to SMC and TNF $\alpha$ treatment. As expected, treatment with SMC resulted in the accumulation of NIK in all three cell lines (Figure 2b and Supplementary Figure 2). In H226, H460 and $\mathrm{H} 661$ cells treated with siRNA targeting combinations of NIK and SMG1, we detected processing and activation of caspase-3 and -8 following combined SMC and TNF $\alpha$ 
a

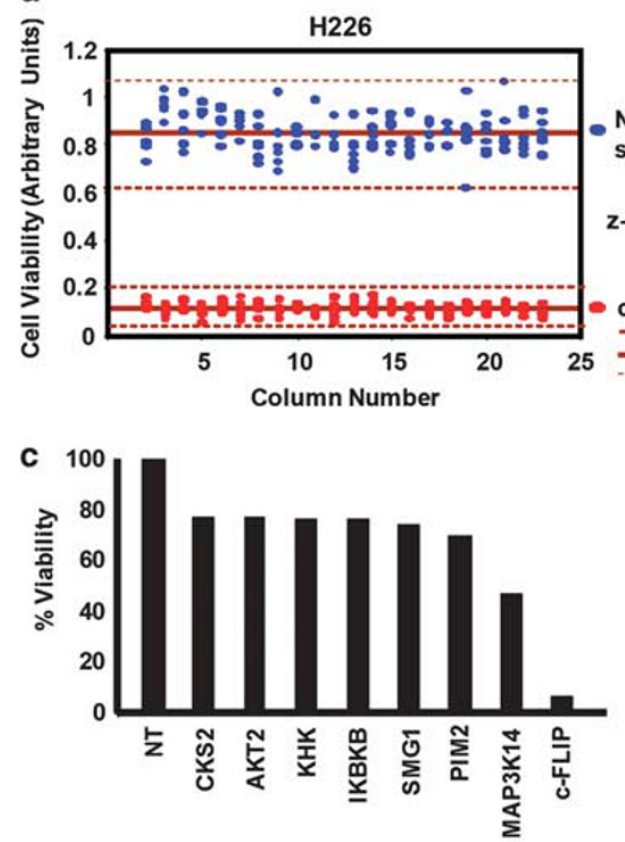

e

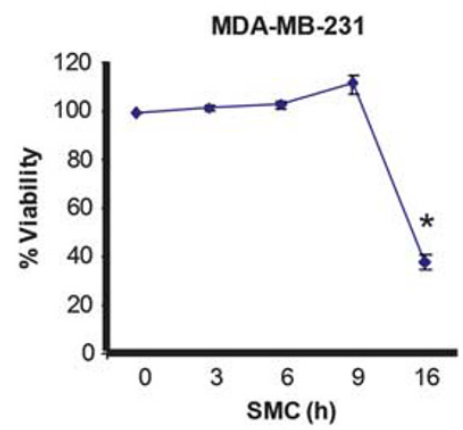

\section{f}

b

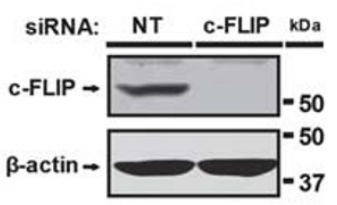

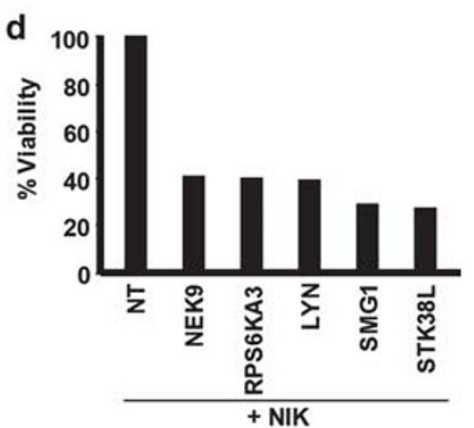

+ NIK

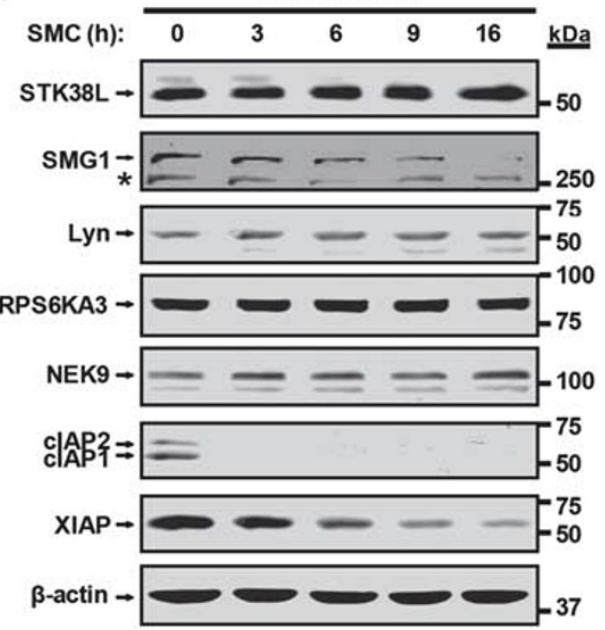

Figure 1 Functional siRNA kinome screens identified NIK and SMG1 as protective factors in SMC-mediated TNF $\alpha$-induced cell death. (a) Evaluation and validation of synthetic lethal siRNA kinome screen. siRNA targeting c-FLIP and a non-targeting (NT) siRNA were printed to 384 -well plates in a checkered pattern. H226 cells were reverse transfected for $24 \mathrm{~h}$ and then treated with $100 \mathrm{nM}$ SMC-AEG40730 and $100 \mathrm{ng} / \mathrm{ml} \mathrm{TNF} \alpha$ for an additional $48 \mathrm{~h}$. Cell viability was determined by Alamar Blue and plotted. The solid horizontal lines show mean readings of the non-targeting and c-FLIP siRNAs. Broken lines represent three S.D. from the mean of each data set. The Z-factor was calculated to be 0.59 , demonstrating the robustness of the screen. (b) $\mathrm{H} 226$ cells were transfected with non-targeting siRNA or c-FLIP-siRNA. At $24 \mathrm{~h}$ post-transfection, cells were harvested and protein expression levels of c-FLIP were analyzed by western immunoblotting. $\beta$-actin was used as a loading control. (c) H226 cells were transfected with siRNA library targeting the human kinome, non-targeting siRNA or c-FLIP-siRNA for $24 \mathrm{~h}$, and then exposed to SMC-AEG40730 and TNF $\alpha$ for $48 \mathrm{~h}$ and cell viability was determined by Alamar Blue. The percentage viability relative to siRNA transfection without drug exposure was plotted for the top hits. MAP3K14 (NIK) was identified as the most potent repressor of cell death. (d) H226 cells were transfected with siRNA targeting NIK in combination with siRNA library targeting the human kinome for $24 \mathrm{~h}$. Transfected cells were then exposed to SMC-AEG40730 and TNF $\alpha$ for an additional $48 \mathrm{~h}$ and cell viability was determined. (e) MDA-MB-231 cells were treated with $100 \mathrm{nM}$ SMC-AEG40730 and cell viability was determined at the indicated times. The percentage viability of MDA-MB-231 cells relative to vehicle \pm S.E.M. from five independent experiments was plotted. ${ }^{*} P<0.001$ significantly different from vehicle, as determined by ANOVA with post hoc Tukey's HSD. (f) MDA-MB-231 cells were treated with $100 \mathrm{nM}$ SMC-AEG40730 (SMC) for 0-16 h. Cells were harvested and protein samples were resolved on SDS-PAGE and western immunoblotted with the indicated antibodies. $\beta$-Actin was used as a loading control. Asterisk denotes a nonspecific band. The pro-survival kinase SMG1 identified in the synthetic lethal kinomic screen was downregulated in SMC-sensitive MDA-MB-231 cells in response to IAP antagonism

treatment (Figure $2 \mathrm{~b}$ and Supplementary Figure 2), in accord with a role for caspases in SMC-mediated cell death. The efficiency of siRNA-mediated SMG1 and NIK knockdown was also confirmed (Figure $2 \mathrm{~b}$ and Supplementary Figure 2).
Next, we analyzed the effects of caspase- 8 or -9 silencing with siRNA in $\mathrm{H} 226$ cells that were depleted of SMG1 and NIK before SMC and $\mathrm{TNF} \alpha$ treatment. Downregulation of caspase-8, but not caspase-9, prevented SMC-mediated 
a

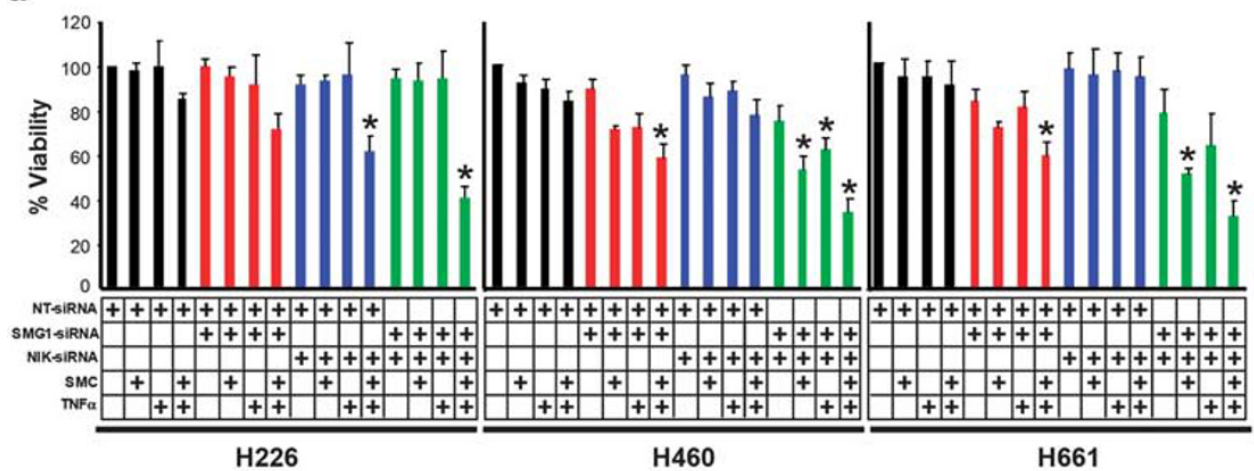

b

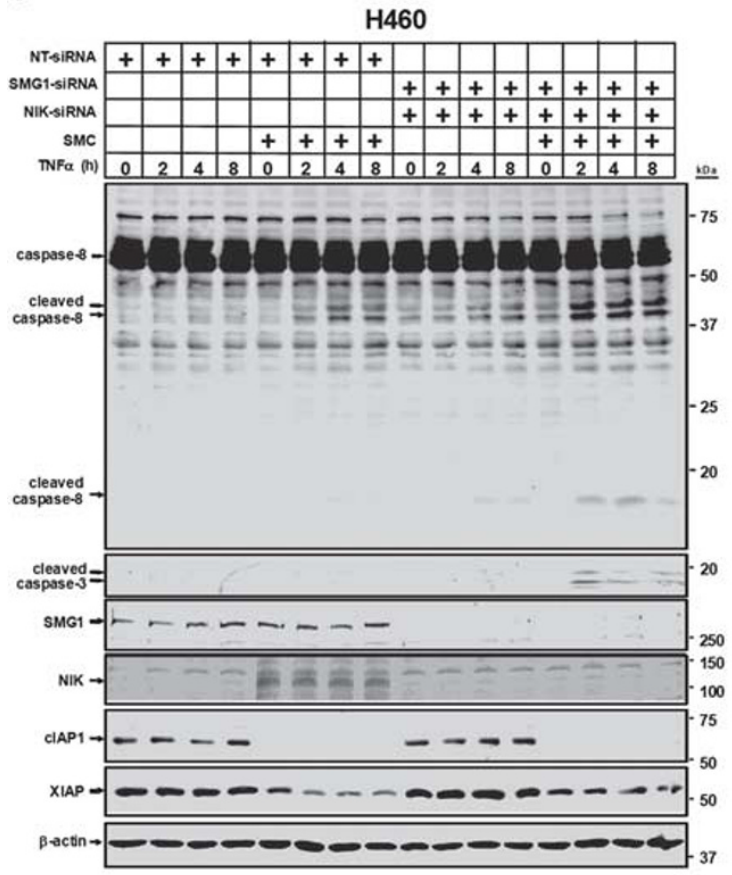

C

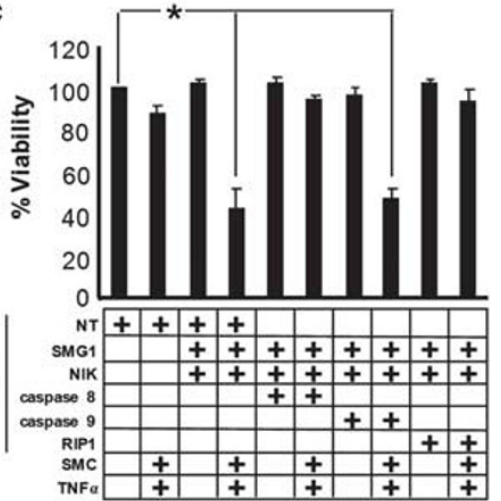

d

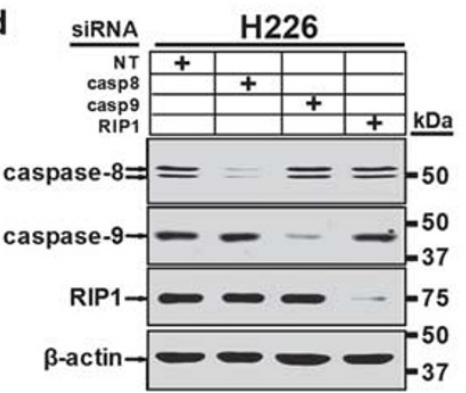

Figure 2 Depletion of SMG1 and NIK promotes SMC-mediated TNF $\alpha$-induced caspase activation. (a) H226, H460 and H661 cells were transfected with siRNA targeting SMG1 (red bars), NIK (blue bars), both (green bars) or non-targeting (NT) siRNA (black bars) as a control. At $24 \mathrm{~h}$ after siRNA-mediated silencing, cells were exposed to combinations of $100 \mathrm{nM}$ SMC-AEG40730 and $100 \mathrm{ng} / \mathrm{ml}$ TNF $\alpha$ for an additional $48 \mathrm{~h}$. Cell viability was determined by Alamar Blue. Numbers represent the average \pm S.E.M. of at least three assays. ${ }^{*} P<0.01$ significantly different from non-targeting siRNA and vehicle, as determined by ANOVA with post hoc Tukey's HSD. (b) H460 cells were transfected with siRNA targeting SMG1, NIK, or non-targeting siRNA as a control. At $24 \mathrm{~h}$ after siRNA-mediated silencing, cells were exposed to SMC for $1 \mathrm{~h}$ before the addition of $100 \mathrm{ng} / \mathrm{ml} \mathrm{TNF} \alpha$. At the indicated times of TNF $\alpha$ treatment, cells were harvested and subjected to western immunoblotting with antibodies recognizing caspase-8, cleaved caspase-3, SMG1, NIK, cIAP1, cIAP2 and XIAP. $\beta$-Actin was used as a loading control. Processing of caspase-8 and -3 were detected in SMG1-and NIK-depleted cells following combined SMC and TNF $\alpha$ treatment. (c) H226 cells were transfected with siRNA targeting SMG1 and NIK, in combination with siRNA targeting caspase-8, -9 or RIP1 for $48 \mathrm{~h}$, and then exposed to SMC and TNF $\alpha$ for an additional $48 \mathrm{~h}$ before cell viability was determined by Alamar Blue. Numbers represent the average \pm S.E.M. of at least three assays. ${ }^{*} P<0.001$ significantly different from non-targeting siRNA and vehicle, as determined by ANOVA with post hoc Tukey's HSD. (d) H226 cells were treated with siRNA as in (c) for $48 \mathrm{~h}$, and isolated proteins were probed by western immunoblotting for the presence of caspase- $8,-9$ and RIP1. The silencing of caspase-8 or RIP1 prevented SMC-mediated TNF $\alpha$-induced cell death in dually NIK- and SMG1-depleted cells

TNF $\alpha$-induced cell death in $\mathrm{H} 226$ cells depleted of SMG1 and NIK (Figure 2c). RIP1 has been suggested to have an important role in SMC-mediated cell death. ${ }^{10,11}$ Accordingly, we analyzed for the effect of RIP1 downregulation in cells that were rendered sensitive to SMC-mediated TNF $\alpha$-induced cell death because of dual downregulation of SMG1 and NIK. Similar to caspase-8 silencing, RIP1 knockdown protected SMG1/NIK-depleted H226 cells from cell death triggered by $\mathrm{SMC}$ and TNF $\alpha$ co-treatment (Figure 2c). The downregulation of caspase-8, -9 and RIP1 by SiRNA was confirmed (Figure 2d). These results indicate that caspase-8 and RIP1 are functional mediators of cell death triggered by SMC and TNF $\alpha$ treatment.

The activation of caspases in SMG1- and NIK-depleted cells in response to SMC and TNF $\alpha$ treatment indicates that apoptosis might be the underlying mechanism of cell death. We next measured apoptosis using flow cytometry by identifying the percentage of cells that are stained with 

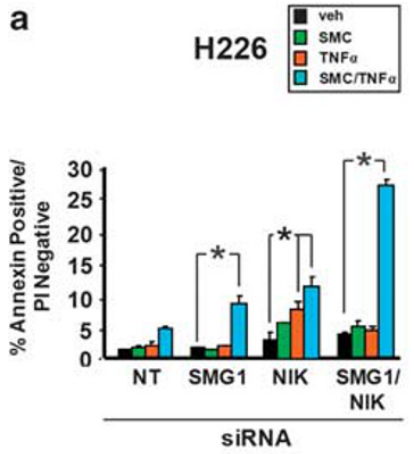

d

$\mid$

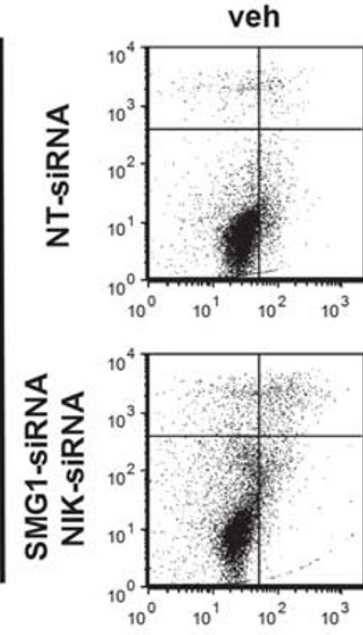

b
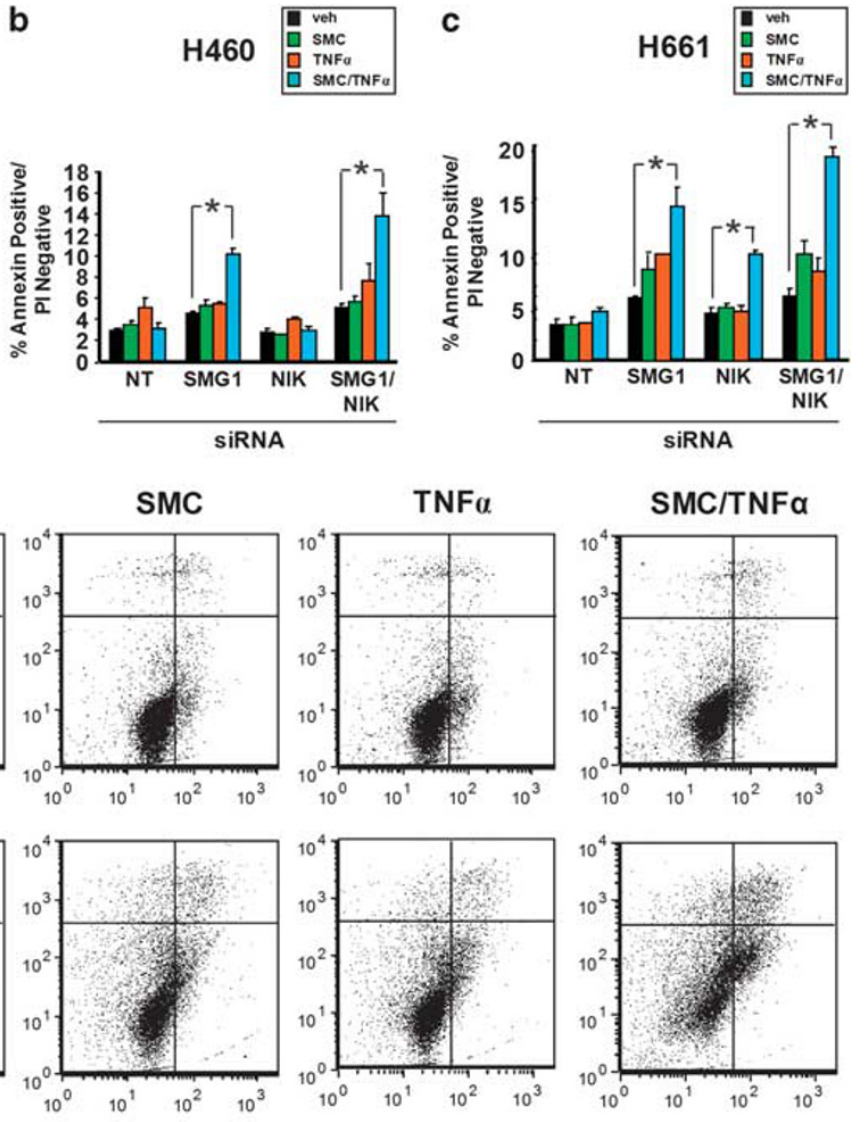

c

H661

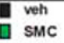

SMC

SMCIN

$\mathrm{SMC} / \mathrm{TNFa}$
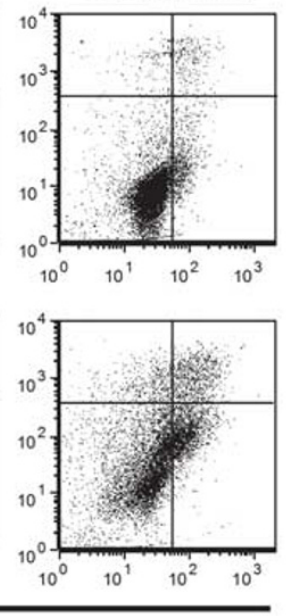

Annexin V-FITC

Figure 3 Depletion of SMG1 and NIK allows cancer cells to undergo apoptosis in response to SMC and TNF $\alpha$ treatment. (a) H226 (b) H460 and (c) H661 cells were transfected with siRNA targeting SMG1, NIK or non-targeting siRNA as a control. At $24 \mathrm{~h}$ after siRNA-mediated silencing, cells were exposed to combinations of $100 \mathrm{nM}$ SMCAEG40730 and $100 \mathrm{ng} / \mathrm{ml} \mathrm{TNF} \alpha$. At $24 \mathrm{~h}$ after drug treatment, cells were stained with annexin $\mathrm{V}$ and propidium iodide to measure the rate of apoptosis by flow cytometry. Plotted numbers represent the average \pm S.E.M. of three independent assays. ${ }^{*} P<0.001$ significantly different from vehicle for the respective siRNA group treated with vehicle, as determined by ANOVA with post hoc Tukey's HSD. (d) Representative dot plots of H460 cells treated as in (b). The downregulation of SMG1 and NIK promoted SMC-mediated TNF $\alpha$-induced apoptosis in cancer cells

annexin V-fluorescein isothiocyanate (FITC) without propidium iodide uptake. Consistent with the activation of caspases, we detected increased apoptosis in response to SMC and TNF $\alpha$ treatment in $\mathrm{H} 226, \mathrm{H} 460$ and $\mathrm{H} 661$ cells depleted of NIK and SMG1 (Figure 3 and Supplementary Figure 3). Notably, the combined downregulation of NIK and SMG1 resulted in a higher apoptotic index than single knockdowns in response to SMC and TNF $\alpha$ treatment (Figure 3 and Supplementary Figure 3). Together, these results are consistent with the ability of SMCs to induce caspase-8-mediated apoptosis upon TNF $\alpha$ treatment.

cIAP1, cIAP2 and XIAP cooperatively protect against TNF $\alpha$-induced cell death in cancer cells depleted of SMG1 and NIK. The underlying mechanism of SMCmediated TNF $\alpha$-induced cell death in cancer cells is attributed to the ability of SMCs to antagonize the clAPs and possibly XIAP. ${ }^{15,25,26}$. To define the contribution of each of these IAPs in blocking TNF $\alpha$-induced cell death, we individually and jointly silenced CIAP1, cIAP2 and XIAP in combination with SMG1 and NIK knockdown before TNF $\alpha$ treatment. The combined silencing of SMG1 and NIK along with the three IAPs was sufficient to decrease $\mathrm{H} 226, \mathrm{H} 460$ and $\mathrm{H} 661$ cell viability, whereas the addition of TNF $\alpha$ promoted more cell death in $\mathrm{H} 226$ cells (Figures $4 \mathrm{a}-\mathrm{c}$ ). We further demonstrated the importance of IAP antagonism by using SM-164, a different SMC that also potently targets the IAPs. ${ }^{15}$ As expected, SM-164 treatment similarly triggered TNF $\alpha$-mediated cell death in H226 cells depleted of SMG1 and NIK (Figure 4d). In accord with results from the kinomic siRNA screens, the single knockdown of SMG1 or NIK also sensitized these IAP-deficient cancer cells to TNF $\alpha$-mediated cell death (Supplementary Figures 4A-I). Downregulation of NIK was more potent at reducing cell viability than SMG1 silencing in IAP-deficient $\mathrm{H} 226$ cells (Supplementary Figures $4 \mathrm{~B}$ and $\mathrm{C}$ ). Conversely, SMG1 knockdown was more effective in promoting cell death than NIK downregulation in IAP-deficient $\mathrm{H} 460$ and $\mathrm{H} 661$ cells (Supplementary Figures 4E, F, H and I). The efficiency of clAP1, clAP2 and XIAP knockdown by siRNA was also confirmed (Figure $4 \mathrm{e}$ and Supplementary Figure 5). These results show that targeting of these three IAPs is the most effective way to induce cancer cell death in SMG1 and NIK-depleted cancer cells. 
SMG1 blunts SMC-mediated TNF $\alpha$-induced JNK activation and C-FLIP turnover by the proteasome. Turnover of c-FLIP is a determinant for SMC-induced cell death through the extrinsic apoptosis pathway. ${ }^{9}$ As SMG1 and NIK silencing allows SMC-mediated TNF $\alpha$-induced cell death to proceed, we reasoned that SMG1 and NIK might affect c-FLIP
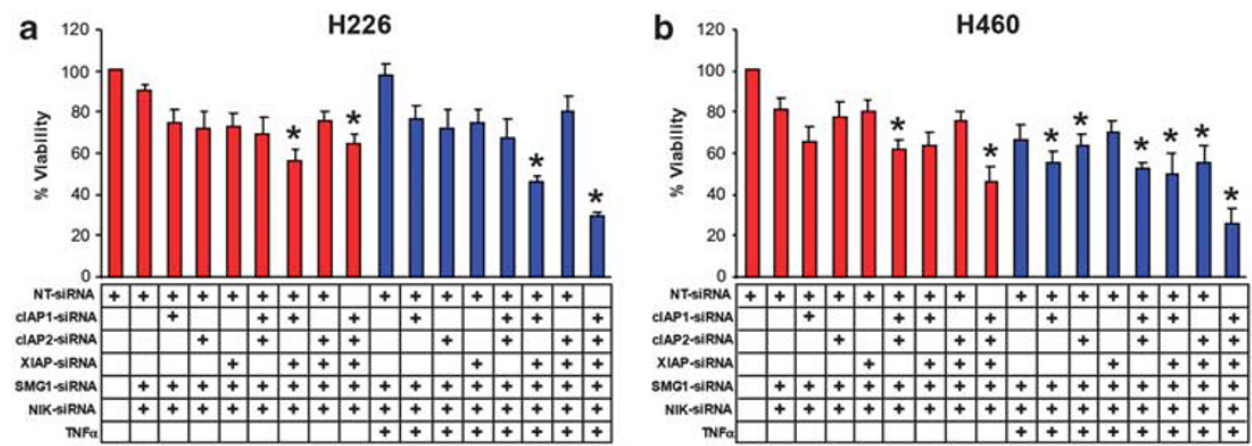

c

H661

d

H226
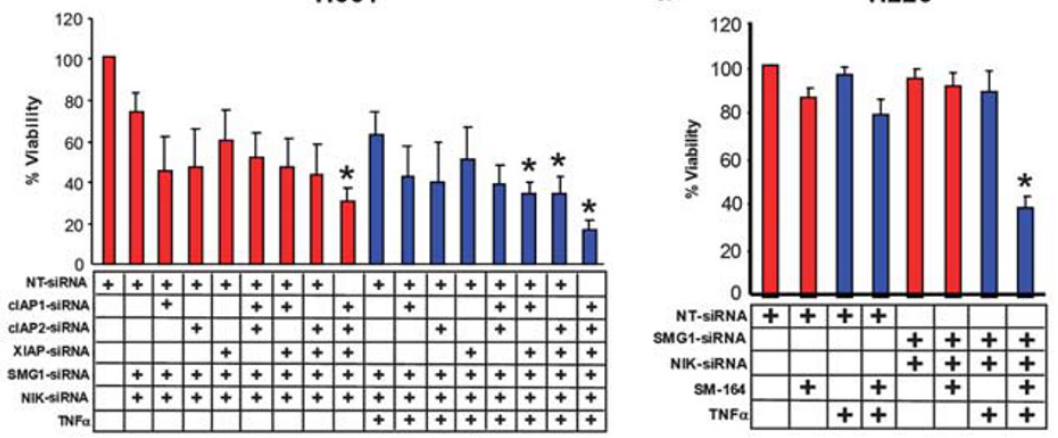

e

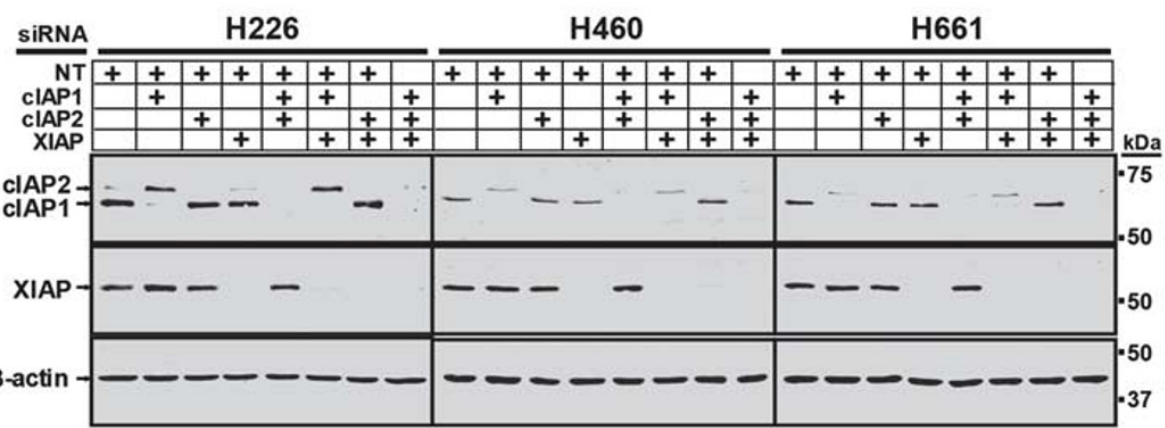

Figure 4 cIAP1, cIAP2 and XIAP cooperatively protect against TNF $\alpha$-induced cell death in cancer cells depleted of SMG1 and NIK. (a) H226, (b) H460 and (c) H661 cells were transfected with siRNA targeting cIAP1, cIAP2, XIAP, SMG1, NIK or non-targeting siRNA as a control. At $48 \mathrm{~h}$ post-transfection, cells were treated with a vehicle (red bars), or with $100 \mathrm{ng} / \mathrm{ml} \mathrm{TNF} \alpha$ (blue bars) for an additional $48 \mathrm{~h}$. (d) H226 cells were transfected with siRNA targeting SMG1, NIK or non-targeting siRNA as a control for $24 \mathrm{~h}$, and then treated with combinations of $100 \mathrm{nM} \mathrm{SM}-164$ and $100 \mathrm{ng} / \mathrm{ml} \mathrm{TNF} \alpha$ for an additional $48 \mathrm{~h}$. Cell viability was determined by Alamar Blue. Numbers represent the average \pm S.E.M. of at least three assays. ${ }^{*} P<0.01$ significantly different from non-targeting siRNA and vehicle, as determined by ANOVA with post hoc Tukey's HSD. (e) H226, H460 and H661 cells were transfected with siRNA targeting clAP1, cIAP2 and XIAP. At $48 \mathrm{~h}$ post-transfection, cells were harvested and protein expression levels of CIAP1, CIAP2 and XIAP analyzed by western immunoblotting. $\beta$-Actin was used as a loading control

Figure 5 SMG1 blunts SMC-mediated TNF $\alpha$-induced JNK activation and c-FLIP turnover by the proteasome. (a) H226, H460 and H661 cells were transfected with siRNA targeting SMG1, NIK or non-targeting siRNA as a control for $24 \mathrm{~h}$, and then exposed to combinations of $100 \mathrm{nM}$ SMC-AEG40730 and $100 \mathrm{ng} / \mathrm{ml}$ TNF $\alpha$ for $24 \mathrm{~h}$. Cells were subsequently harvested and the protein expression levels of c-FLIP, SMG1 and NIK were determined by western immunoblotting. Asterisk denotes a nonspecific band. (b) $\mathrm{H} 460$ and $\mathrm{H} 661$ cells were transfected with siRNA targeting SMG1, NIK or non-targeting siRNA as a control. At $24 \mathrm{~h}$ post-transfection, cells were first exposed to $100 \mathrm{nM}$ SMC-AEG40730 for $1 \mathrm{~h}$, then treated with $100 \mathrm{ng} / \mathrm{ml} \mathrm{TNF} \alpha$ in combination with vehicle, $20 \mu \mathrm{M}$ Gliotoxin, $20 \mu \mathrm{M}$ MG132 or $2 \mu \mathrm{M}$ MG262 for an additional $4 \mathrm{~h}$. Cells were harvested and c-FLIP, SMG1 and NIK protein levels were determined. $\beta$-Actin was used as a loading control. Inhibition of the proteasome prevented SMC-mediated TNF $\alpha$ induced c-FLIP turnover. (c) MDA-MB-231 cells were treated with $100 \mathrm{nM}$ SMC-AEG40730 (SMC) for 0-16 h. Cells were harvested, protein samples were resolved on SDSPAGE and western immunoblotted with antibodies against c-FLIP, phospho-JNK and total JNK. (d) H460 and H661 cells were transfected with siRNA targeting SMG1, NIK or non-targeting siRNA as a control for $24 \mathrm{~h}$, and then exposed to $100 \mathrm{nM}$ SMC-AEG40730 for $1 \mathrm{~h}$ before the addition of $100 \mathrm{ng} / \mathrm{ml} \mathrm{TNF} \alpha$ for the indicated times. Harvested cells were processed for protein and analyzed for JNK activation by western immunoblotting. SMG1 knockdown enhances TNF $\alpha$-mediated JNK activation in SMC-treated cells 
levels in response to SMC and TNF $\alpha$ treatment. We found that in SMG1- and NIK-depleted cells, c-FLIP levels decreased in response to the combined treatment of SMC and TNF $\alpha$ (Figure 5a). To determine the process that regulates c-FLIP metabolism, we next screened an inhibitor library that covers a wide spectrum of proteases (Supplementary Table 1). We identified proteasome inhibitors gliotoxin and MG132 as the most potent blockers of c-FLIP downregulation in dually a

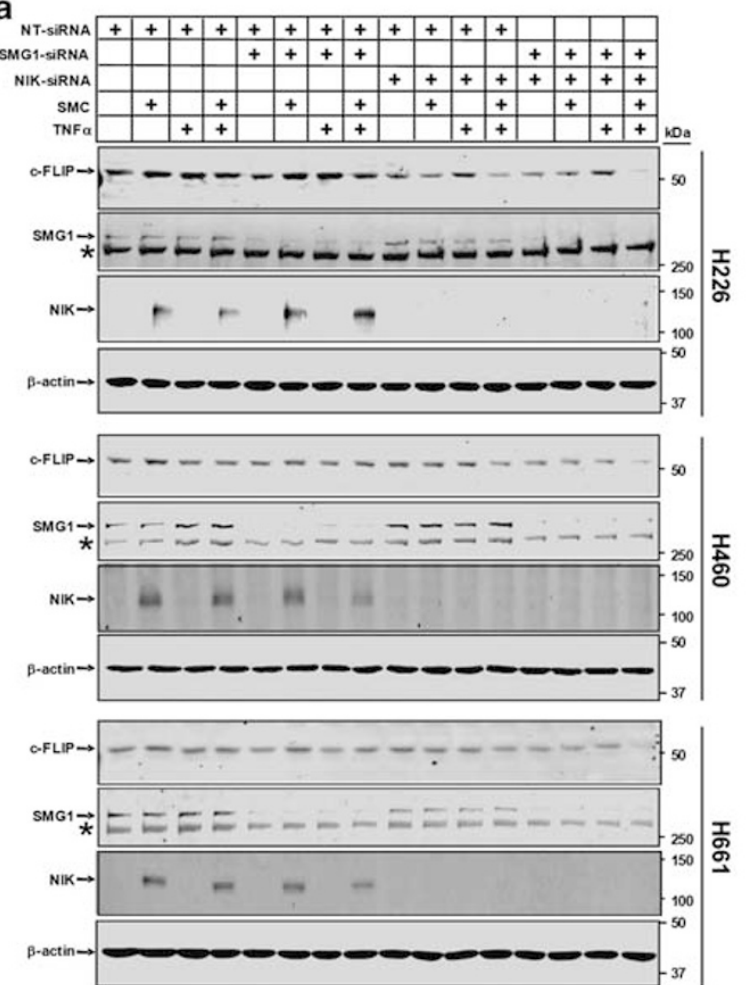

b

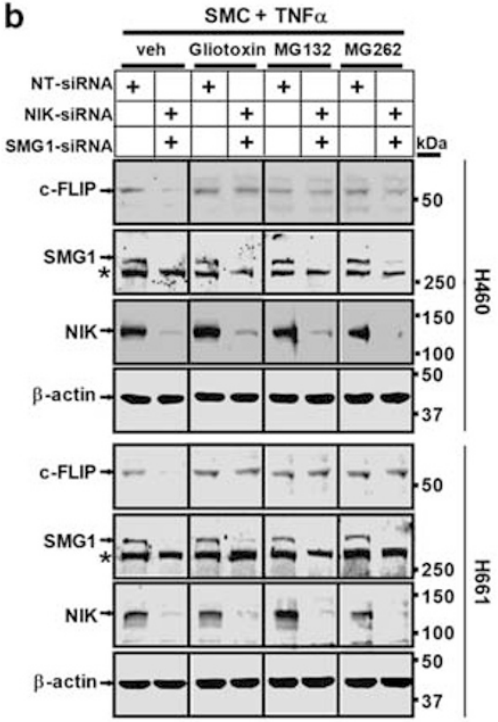

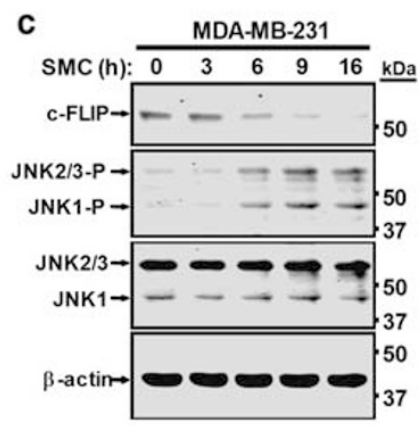

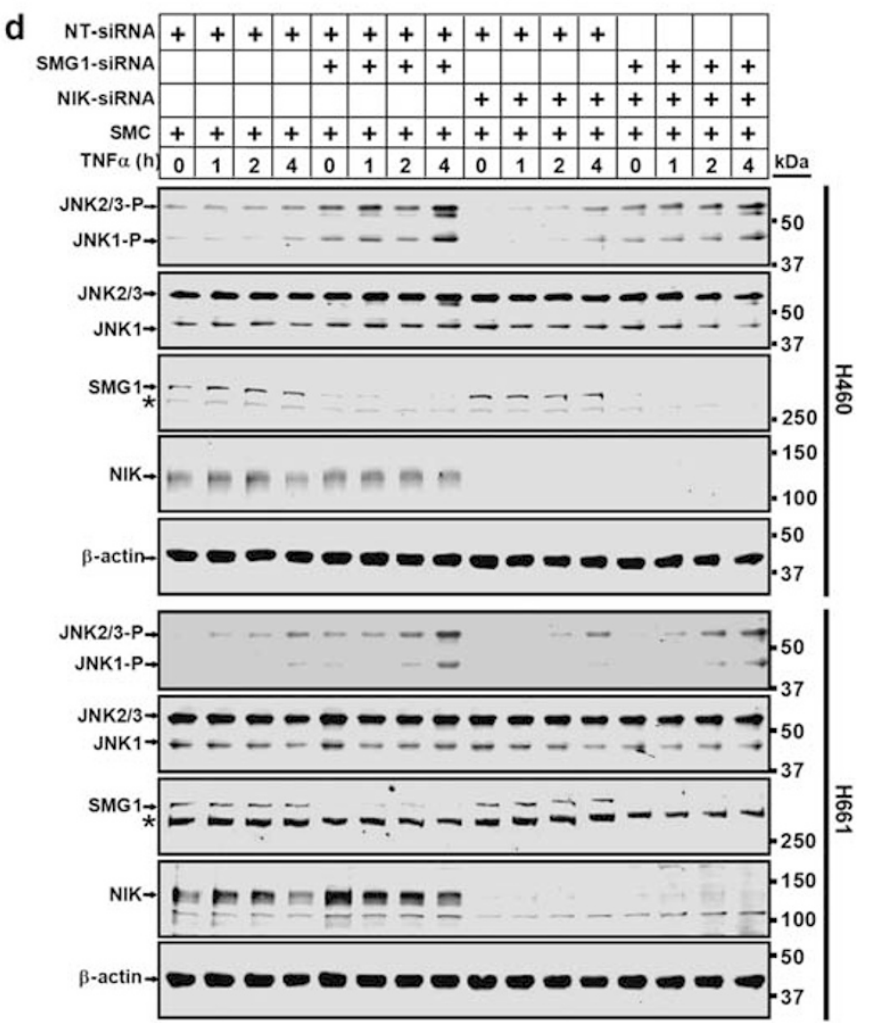


SMG1- and NIK-depleted $\mathrm{H} 460$ and $\mathrm{H} 661$ cells treated with SMC and TNF $\alpha$ (Figure 5b and Supplementary Figure 6). In addition, the proteasome inhibitor MG262 similarly prevented c-FLIP degradation (Figure 5b). These results indicate that the proteasome has a major role in SMC-mediated c-FLIP turnover triggered by $\mathrm{TNF} \alpha$.

JNK-mediated activation of the ubiquitin-proteasome pathway can facilitate the downregulation of c-FLIP. ${ }^{27}$ We have previously shown that in cancer cell lines resistant to SMC treatment, JNK activation is repressed in response to $\mathrm{TNF} \alpha .{ }^{9}$ In contrast, SMC treatment activates the JNK pathway in MDA-MB-231 cells, a SMC-sensitive cell line (Figure 5c). We therefore examined for the activation of JNK in response to SMC and TNF $\alpha$ treatment in SMG1- and NIKdepleted cells. In $\mathrm{H} 460$ and $\mathrm{H} 661$ cells treated with SMC, silencing of SMG1, but not NIK, led to increased TNF $\alpha$ mediated activation of JNK1, JNK2 and JNK3 (Figure 5d). Together, these data suggest that SMG1 represses JNK activity and prevents c-FLIP degradation by the proteasome in response to SMC and TNF $\alpha$ treatment.

\section{Upregulation of NIK by SMC treatment activates both the classical and alternative NF- $\kappa$ B pathways and enhanced C-FLIP transcription. As NIK did not regulate c-FLIP levels via the JNK pathway, we next investigated the possibility that $\mathrm{NIK}$, as a modulator of nuclear factor $-\kappa \mathrm{B}(\mathrm{NF}-\kappa \mathrm{B})$ pathway, might regulate $\mathrm{c}-\mathrm{FLIP}$ transcription. Activation of alternative NF $-\kappa \mathrm{B}$ pathway requires the processing of phosphorylated- p100 to produce $p 52 .{ }^{28}$ Phosphorylation of $p 100$ can be either directly catalyzed by $\mathrm{NIK}$ or indirectly via IKK $\alpha$ dimers. ${ }^{28}$ Furthermore, activated NIK can cross-talk with the classical NF- $\kappa \mathrm{B}$ pathway through the NIK-IKK complex. ${ }^{29}$ In response to SMC treatment, NIK protein levels accumulated in $\mathrm{H} 226$, H460 and $\mathrm{H} 661$ cells (Figure 2B and Supplementary Figure 2), thereby promoting the production of p52 (Figures 6a and c). As expected, when NIK was silenced by siRNA, production of p52 decreased in response to SMC treatment (Figures 6a and c). Downregulation of SMG1 showed no effect on either NIK levels or p52 production (Figures 2b, 6a and c, Supplementary Figure 2). Moreover, SMC treatment promoted persistent phosphorylation of $\mathrm{p} 65$, indicating that the classical NF- $\kappa \mathrm{B}$ pathway was also activated (Figure 6c). Silencing of NIK, but not SMG1, repressed SMC-mediated phosphorylation of p65 (Figure $6 \mathrm{c}$ ). As the increase in NF- $\kappa \mathrm{B}$ activity may modulate c-FLIP transcription, ${ }^{30}$ we next assessed for c-FLIP mRNA levels after SMC and TNF $\alpha$ treatment. In H226 cells, c-FLIP mRNA levels markedly increased in response to SMC and TNF $\alpha$ treatment (Figure 6b). Knockdown of NIK, but not SMG1, blocked the increase in c-FLIP mRNA levels (Figure 6b). Similarly, NIK knockdown reduced c-FLIP messages in $\mathrm{H} 460$ and $\mathrm{H} 661$ cells treated with SMC and $\mathrm{TNF} \alpha$ (Supplementary Figure 7). Therefore, these results indicate that NIK upregulation by SMC treatment activates both the classical and alternative NF- $\kappa$ B pathways and may maintain c-FLIP levels by enhancing the amount of c-FLIP transcripts.}

Downregulation of IAPs and c-FLIP leads to cancer cell death. Silencing of endogenous SMG1 and NIK sensitizes cancer cells to SMC-mediated TNF $\alpha$-induced cell death (Figures 1-3 and Supplementary Figure 3). Similarly, siRNA-

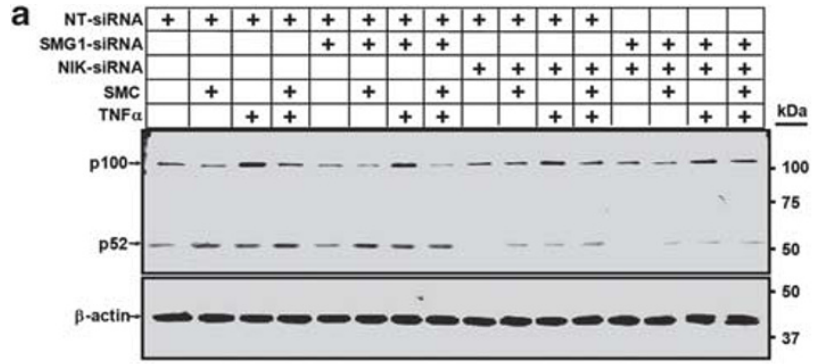

b
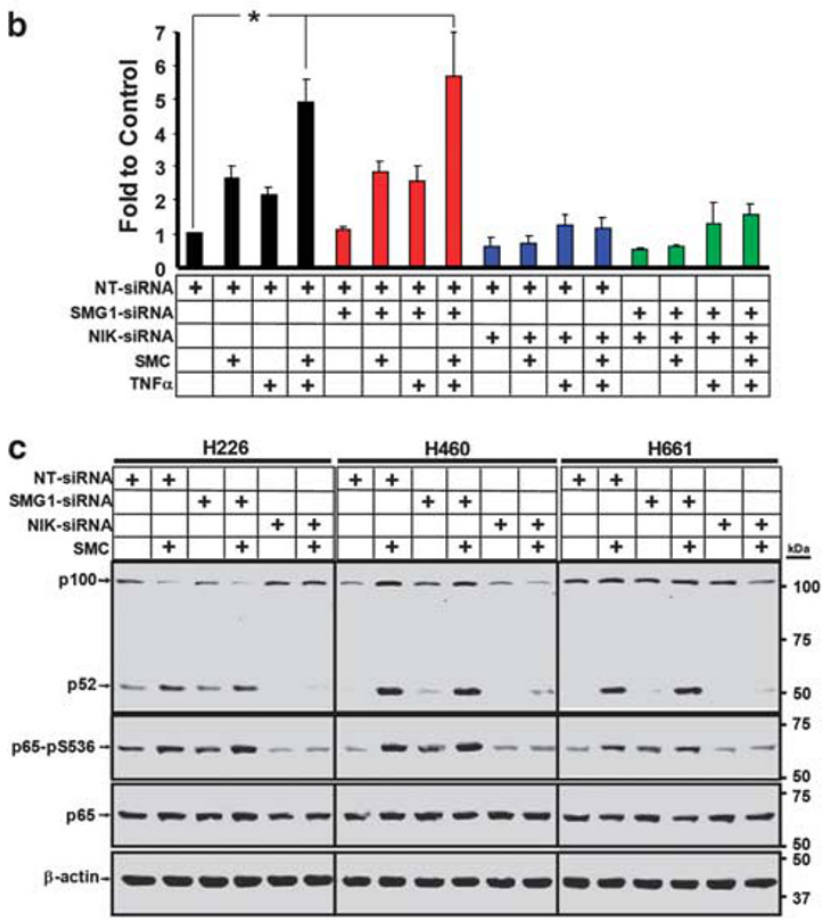

Figure 6 SMC treatment activates both the classical and alternative NF- $\kappa B$ pathways via NIK, promoting c-FLIP transcription. (a) H226 cells were transfected with siRNA targeting SMG1, NIK or non-targeting siRNA as a control for $24 \mathrm{~h}$, and then exposed to combinations of $100 \mathrm{nM} \mathrm{SMC-AEG40730} \mathrm{and} 100 \mathrm{ng} / \mathrm{ml}$ TNF $\alpha$ for an additional $24 \mathrm{~h}$. Cells were harvested and subjected to western immunoblotting with antibodies recognizing p100 and p52. $\beta$-Actin was used as a loading control. (b) H226 cells treated as in (a) were harvested and RNA was isolated for real-time qRT-PCR to determine c-FLIP mRNA levels. Fold changes from four independent experiments relative to non-targeting siRNA and vehicle \pm S.E.M. normalized against GAPDH mRNA levels were plotted; siRNA targeting SMG1: red bars; NIK: blue bars; both: green bars; non-targeting siRNA: black bars. Numbers represent the average \pm S.E.M. of at least three assays. ${ }^{*} P<0.001$ significantly different from non-targeting siRNA and vehicle, as determined by ANOVA with post hoc Tukey's HSD. (c) H226, $\mathrm{H} 460$ and $\mathrm{H} 460$ cells were transfected with siRNA targeting SMG1, NIK or non-targeting siRNA as a control. At $24 \mathrm{~h}$ post-transfection, cells were treated with $100 \mathrm{nM}$ SMC-AEG40730 for an additional $24 \mathrm{~h}$. Cells were then harvested and subjected to western immunoblotting with antibodies recognizing p100, p52, phospho-p65 and p65. Downregulation of NIK blocks SMC-induced activation of the classical and alternative NF- $\kappa$ B pathways, as well as SMC- and TNF $\alpha$-mediated induction of $c$-FLIP transcripts

mediated downregulation of SMG1 and NIK in combination with IAP silencing also promoted cell death (Figure 4 and Supplementary Figure 4). The ability of SMG1 and NIK to maintain TNF $\alpha$-regulated c-FLIP levels in response to SMC 
a

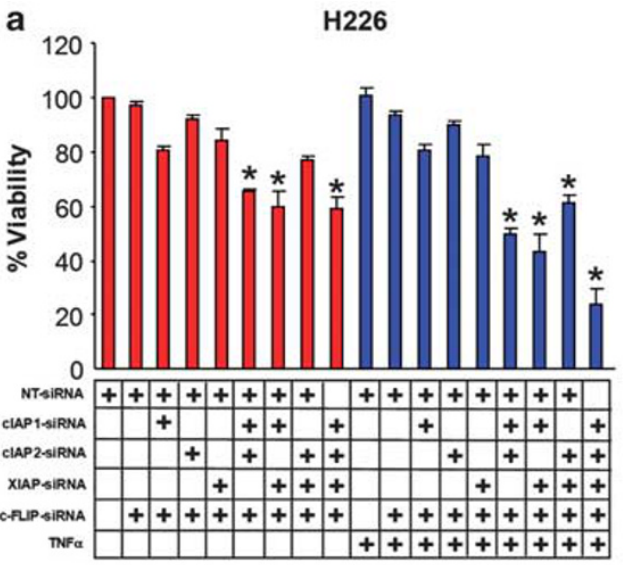

b

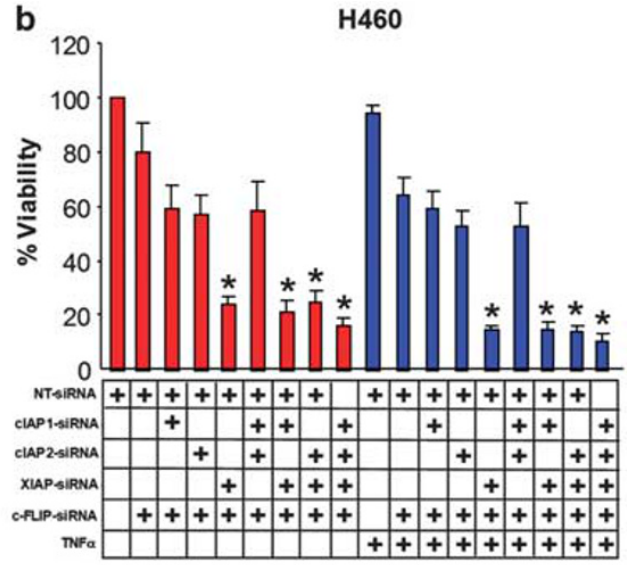

C

H661

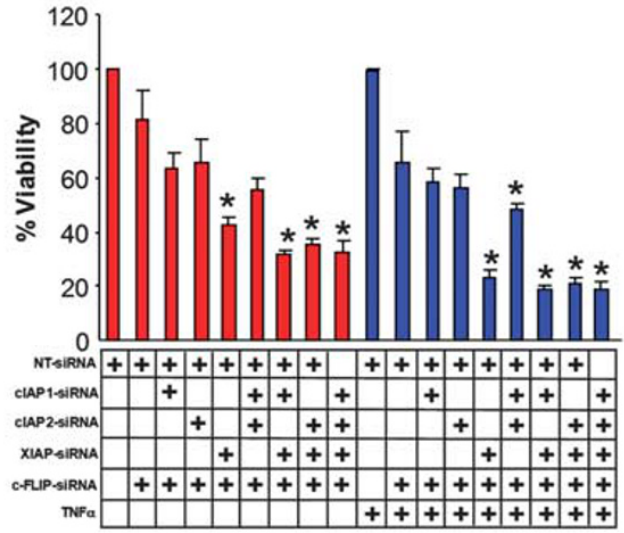

Figure 7 Downregulation of IAPs and c-FLIP leads to cancer cell death. (a) H226, (b) H460 and (c) H661 cells were transfected with siRNA targeting clAP1, cIAP2, XIAP, c-FLIP or non-targeting siRNA as a control. At $48 \mathrm{~h}$ post-transfection, cells were exposed to $100 \mathrm{ng} / \mathrm{ml}$ TNF $\alpha$ for an additional $48 \mathrm{~h}$ before subjected to a cell viability assay. Numbers represent the average \pm S.E.M. of at least four assays. ${ }^{*} P<0.001$ significantly different from non-targeting siRNA samples treated with vehicle, as determined by ANOVA with post hoc Tukey's HSD

treatment (Figures 5 and 6) suggests that the IAPS and c-FLIP act in concert to protect cells from TNF $\alpha$-initiated death signals. Accordingly, we sought to determine the individual and combined contribution of clAP1, clAP2, XIAP and $\mathrm{c}$-FLIP on TNF $\alpha$-mediated cell death. In H226 cells, combined downregulation of c-FLIP, cIAP1 and XIAP markedly decreased cell viability that was further sensitized by the addition of TNF $\alpha$ (Figure 7a). In H460 and H661 cells, downregulation of any one of the three IAPs along with c-FLIP promoted cell death and the effects were the most pronounced with the dual knockdown of XIAP and c-FLIP (Figures $7 \mathrm{~b}$ and c). Remarkably, the knockdown of XIAP and c-FLIP in $\mathrm{H} 460$ cells induced significant cell death (Figure 7b). Together, these results show that endogenous IAPs and c-FLIP are crucial in maintaining cancer cell viability.

\section{Discussion}

SMG1 and NIK are novel repressors of SMC-mediated TNF $\alpha$-induced apoptosis. SMCs are rationally designed small molecules for cancer therapies that target the IAPs. The ability of SMCs to induce TNF $\alpha$-dependent cell death depends on the molecular signature of the cancer cell. $^{9}$ Although the basic components necessary for the execution of cell death by SMCs are relatively well-defined, the underlying molecular pathways involved in SMCresistance in the presence of exogenous $\mathrm{TNF} \alpha$ remain poorly understood. Here, we utilized a functional siRNA kinomic screen to identify factors involved in SMCresistance. We show that the protein kinases NIK and SMG1 have important roles in protecting cancer cells from SMC-mediated TNF $\alpha$-induced apoptosis, likely through sustaining expression levels of c-FLIP that corresponds to the long isoform. ${ }^{31}$ Specifically, SMG1 may maintain c-FLIP levels by repressing JNK activation that consequently prevents proteasomal degradation of C-FLIP, whereas NIK may maintain transcriptional levels of c-FLIP mRNA by activating both the classical and alternative NF- $\kappa$ B pathways (Figure 8).

The dual role of NIK in SMC-mediated apoptosis. The identification of NIK as a protective factor in SMC-mediated TNF $\alpha$-induced apoptosis underscores the duality of the $\mathrm{NF}-\kappa \mathrm{B}$ pathway. The loss of clAP1 and clAP2 by SMC treatment allows for the accumulation of NIK, ${ }^{16,17,32}$ a critical 


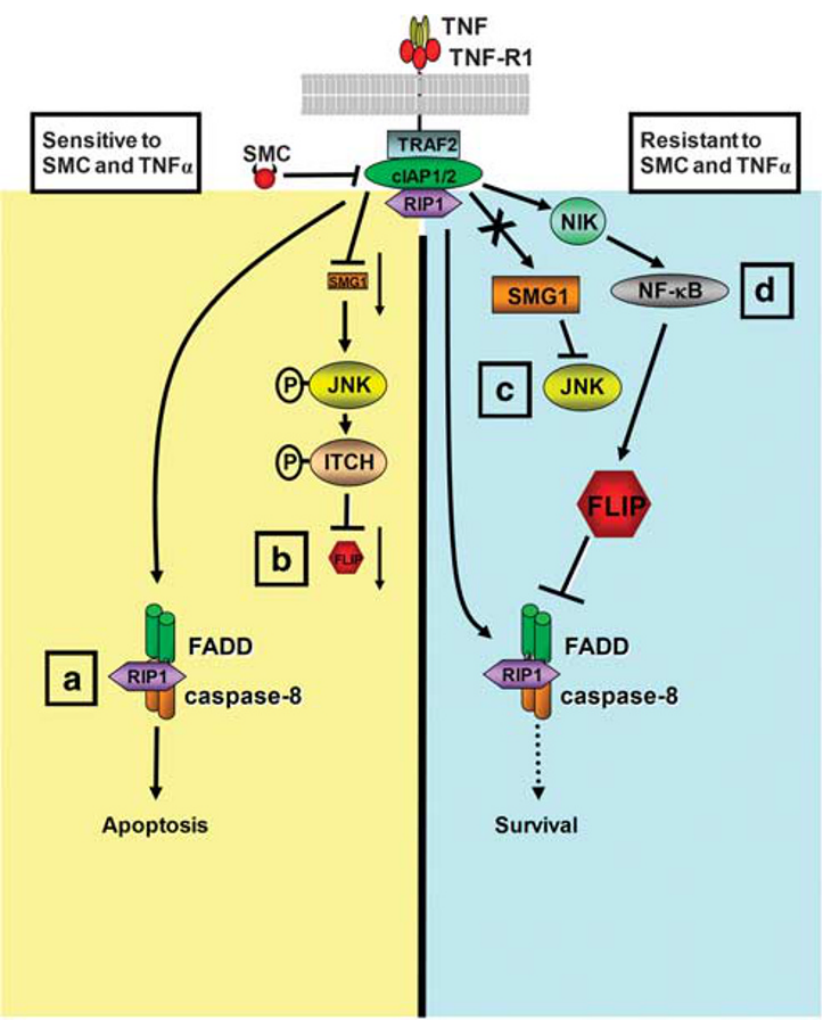

Figure 8 Proposed schematic of the roles of NIK and SMG1 in sensitive versus resistant cells in response to SMC and TNF $\alpha$ treatment. In SMC sensitive cells (left side), removal of the CIAPs by SMC treatment prevents ubiquitination of RIP1, allowing RIP1 to bind and activate the death complex II that includes caspase-8 and FADD (A). Degradation of SMG1 allows for the activation of JNK in response to TNF $\alpha$, leading to proteasomal downregulation of c-FLIP possibly through the ITCHmediated pathway (B). As c-FLIP is downregulated, caspase-8 activation is able to proceed and apoptosis ensues. In SMC-resistant cells (right side), the level of SMG1 persists in spite of SMC and TNF $\alpha$ treatment, blunting the activation of JNK (C) and thereby preventing proteasomal degradation of c-FLIP. In addition, depletion of cIAPs by SMC treatment allows NIK to accumulate, resulting in activation of both the classical and alternative NF- $\kappa B$ pathways (D), which may elevate transcriptional levels of c-FLIP. SMG1 and NIK functions appear to converge by sustaining the protein expression level of c-FLIP, thereby preventing caspase-8 activation and repressing SMC-mediated apoptosis. Silencing of both SMG1 and NIK converts SMC-resistant cells to become sensitive to SMC treatment in response to $\mathrm{TNF} \alpha$

regulator that activates the alternative NF- $\kappa$ B pathway, but also cross-talks to activate the classical NF- $\kappa$ B pathway. ${ }^{29}$ In SMC-sensitive cell lines, activation of the NF- $\kappa$ B pathways upregulates TNF $\alpha$ levels, ${ }^{16,17}$ which acts in an autocrine manner to facilitate SMC-mediated apoptosis. ${ }^{18}$ By comparison, our current findings show that in SMCresistant cell lines, NIK is pro-survival and can activate NF- $\kappa$ B pathways that may sustain $c$-FLIP expression. The consequence of persistent c-FLIP expression is the suppression of apoptosis, as C-FLIP inhibits caspase-8 to block the progression of cell death. ${ }^{33,34}$ Hence, the role for NIK in SMC-mediated cell death reflects the reliance of cancer cells on both NF- $\kappa$ B pathways for the balance between survival and death.

SMG1 and C-FLIP are potential biomarkers for SMC responsiveness. Our studies also identified SMG1 as another repressor of SMC-mediated TNF $\alpha$-induced apoptosis. SMG1 has been previously linked to diverse cellular responses including oxidative stress, hypoxia, $\mathrm{TNF} \alpha$ mediated signalling, and mRNA surveillance mechanisms regulating nonsense-mediated mRNA decay. ${ }^{35-38}$ We propose that a connection exists between SMG1 and c-FLIP turnover through the JNK signalling pathway. Notably, we previously reported that in SMC-resistant cells, TNF $\alpha$-mediated activation of JNK is repressed following SMC treatment. $^{9}$ In contrast, knockdown of SMG1 in SMCresistant cells allows downstream JNK signalling to proceed. Activated JNK can in turn phosphorylate ITCH, an ubiquitin E3 ligase that has been linked to facilitate c-FLIP turnover in a proteasome-dependent manner, ${ }^{27,39}$ a property that is consistent with our observation that C-FLIP metabolism is blocked by proteasome inhibitors. Furthermore, we found that SMC-induced loss of SMG1 in SMC-sensitive MDA-MB-231 cells is correlated with prolonged JNK activation and C-FLIP downregulation. Given these observations, we propose that the downregulation of SMG1 and c-FLIP might serve as functional biomarkers for SMC responsiveness.

Targeting IAPs and c-FLIP: implications for cancer therapy. Our results raise the prospect of addressing the potential obstacles faced with IAP-targeting strategies in cancer therapies. Notably, the combined knockdown of XIAP and C-FLIP was sufficient to cause marked cell death in NSCLC H460 and H661, even in the absence of exogenous $\mathrm{TNF} \alpha$, suggesting a heightened reliance on XIAP and c-FLIP for survival in certain cancer cells. ${ }^{40}$ Moreover, SMC-induced apoptosis and MDA-MB-231 xenograft tumour regression were found to be the most effective when SMCs potently target CIAP1, cIAP2 and XIAP concurrently. ${ }^{15}$ Overall, these results imply that the combination of a pan-IAP SMC and c-FLIP silencing would maximize cancer cell death.

The deciphering of SMC mode of action will have significant implications on the applicability of SMCs as an emerging cancer therapeutic. Our strategy demonstrates the power of coupling functional siRNA and focused chemical screens with a rational targeted approach to investigate the underlying mechanism of biological processes. We have previously established that the silencing of c-FLIP by siRNA reverses SMC-resistance in a broad range of cancer cell lines to extrinsic apoptosis triggers such as TNF $\alpha$ and TRAIL. ${ }^{9}$ We now show that NIK and SMG1 are potential regulators of c-FLIP level at distinct points in SMC-resistant cancer cells. These findings provide novel insight into the complex mechanism of SMC-mediated apoptosis and identify NIK and SMG1 as candidate therapeutic targets for SMC sensitization.

\section{Materials and Methods}

Reagents. SMC AEG40730 ${ }^{6}$ was synthesized by Vibrant Pharma Inc. (Brantford, ON, Canada). SMC SM-164 was kindly provided by Dr. Shaomeng Wang (University of Michigan). ${ }^{15}$ Protease inhibitor library (version 2.0), gliotoxin and MG-132 and TNF $\alpha$ were obtained from Enzo Life Sciences (Farmingdale, NY, USA). MG-262, was obtained from Calbiochem (Gibbstown, NJ, USA). VP16, staurosporine and cycloheximide were obtained from Sigma (St. Louis, MO, USA). 
Cell culture. MDA-MB-231 breast carcinoma, NCl-H226 (H226), NCl-H460 (H460) and NCl-H661 (H661) cells were obtained from ATCC (Manassas, VA, USA) and maintained at $37^{\circ} \mathrm{C}$ and $5 \% \mathrm{CO}_{2}$ in DMEM media supplemented with $10 \%$ heat-inactivated fetal calf serum, penicillin, streptomycin and $1 \%$ non-essential amino acids (all from Invitrogen, Burlington, ON, Canada).

Functional siRNA-based synthetic lethal screen validation. For the development of a functional siRNA-based synthetic lethal screen that would identify protective factors against SMC treatment, $\mathrm{H} 226$ cells were selected because of their strong resistance toward SMC-mediated TNF $\alpha$-induced cell death. ${ }^{9}$. siRNA targeting c-FLIP was used as a positive control as c-FLIP has been previously identified as a protective factor against SMC treatment. ${ }^{9}$ siRNA targeting c-FLIP (Dharmacon ON-TARGETplus SMARTpool, Lafayette, CO, USA) and non-targeting siRNA (Dharmacon Accell) were printed to 384-well plates in a checkered pattern. H226 cells were reversed transfected with $10 \mathrm{nM}$ siRNA using DharmaFECT । (Dharmacon) for $24 \mathrm{~h}$, followed by treatment of $100 \mathrm{nM} \mathrm{SMC-AEG40730} \mathrm{and}$ $100 \mathrm{ng} / \mathrm{ml} \mathrm{TNF} \alpha$ for an additional $48 \mathrm{~h}$. Cell viability was determined by resazurin/ Alamar Blue vital dye (Sigma-Aldrich) that measures mitochondrial metabolic activity. ${ }^{20}$ The results were analyzed to determine the two extremes of activity range and robustness of the screening assay. The screening window coefficient, or Z-factor, was determined as followed: ${ }^{21}$

$$
Z=1-\frac{\left(3 \sigma_{\mathrm{FLIP}}+3 \sigma_{\mathrm{NT}}\right)}{\left|\mu_{\mathrm{FLIP}}-\mu_{\mathrm{NT}}\right|}
$$

A Z-factor $>0.5$ represented an excellent assay suitable for high-throughput screening.

Kinome siRNA screening. A human kinome library containing 691 siRNAs targeting genes that encode for protein kinases, lipid kinases, carbohydrate kinases and regulatory subunits was obtained from Qiagen (Mississauga, ON, Canada). Each siRNA duplex from the kinome library was printed to 384-well plates that also contained designated wells with siRNA targeting c-FLIP or non-targeting siRNA. H226 cells were reversed transfected with $10 \mathrm{nM}$ siRNA using DharmaFECT I. At $24 \mathrm{~h}$ post-transfection, cells in paired plates were treated with either vehicle or $100 \mathrm{nM}$ SMC-AEG40730 and $100 \mathrm{ng} / \mathrm{ml}$ TNF $\alpha$. At $48 \mathrm{~h}$ post-drug exposure, cell viability was assessed by Alamar Blue, and the percentage viability was calculated as the ratio of siRNA treatment in the presence of drugs to vehicle treatment. Singly synthetic lethal siRNAs ( $<50 \%$ viability) were excluded from further analysis. For the NIK-siRNA-coupled screen, cells were transfected with $2 \mathrm{nM}$ siRNA targeting $\mathrm{NIK}$ in addition to the individual genes in the library. At $24 \mathrm{~h}$ post-transfection, cells were treated with SMC-AEG40730 and TNF $\alpha$ for an additional $48 \mathrm{~h}$ and cell viability was determined.

Additional siRNAs targeting SMG1, NIK, CIAP1, cIAP2, XIAP, caspase-8, -9 and RIP1 were obtained from Dharmacon (ON-TARGETplus SMARTpool). A nontargeting pool siRNA control (Dharmacon) was used as an RNA interference control for all siRNA transfections.

Western immunoblotting. Cells were collected by centrifugation and lysed in $50 \mathrm{mM}$ Tris- $\mathrm{HCl}$, pH 8.0. containing 1\% Triton X-100, $150 \mathrm{mM} \mathrm{NaCl}, 1 \mathrm{mM} \mathrm{NaF}$, $0.1 \mathrm{mM}$ phenylmethylsulfonyl fluoride, $5 \mu \mathrm{g} / \mathrm{ml}$ pepstatin A and $10 \mu \mathrm{g} / \mathrm{ml}$ each of leupeptin and aprotinin (lysis buffer) and insoluble materials were pelleted by centrifugation at $12000 \times g$ for $30 \mathrm{~min}$ at $4{ }^{\circ} \mathrm{C}$. Supernatants were collected for protein determination by Bio-Rad (Mississauga, ON, Canada) Protein Assay using bovine serum albumin as a standard. Samples were solubilized with sample buffer $(62.5 \mathrm{mM}$ Tris- $\mathrm{HCl}, \mathrm{pH} 6.8$ containing $2 \%$ SDS, $1 \% \beta$-mercaptoethanol and $5 \%$ glycerol), and equal amounts of samples were separated on polyacrylamide gels followed by transferred to nitrocellulose. Following protein transfer, individual proteins were detected by western immunoblotting using the following antibodies recognizing: $\beta$-actin (clone AC-15) from Sigma; cleaved caspase-3 (9661), caspase-9 (9502), JNK (9252), phospho(T183/Y185)-JNK (9251), Lyn (clone 5G2), NIK (4994), p100/p52 (4882), p65 (clone C22B4), phosphor(S536)-p65 (clone 93H1) and SMG1 $(4993,9592)$ from Cell Signaling Technology (Danvers, MA, USA); caspase-8 (AHZ0502) from Invitrogen; c-FLIP (clone NF6) from Alexis Biochemicals (Lausen, Switzerland); RPS6KA3 (TA303691) from Origene (Rockville, MD, USA); NEK9 (ab71812) and STK38L (ab84873) from Abcam (Cambridge, MA, USA); and RIP1 (clone 38) from BD Biosciences (Franklin Lakes, NJ, USA). Our rabbit anti-rat IAP1 and IAP3 polyclonal antibodies were used to detect cIAP $1 / 2$ and XIAP, respectively. ${ }^{7}$ Bound primary antibodies were reacted with secondary antibodies conjugated to AlexaFluor680 (Invitrogen) or IRDye800
(Rockland, Gilbertsville, PA, USA) and the infrared fluorescent signals were detected using the Odyssey Infrared Imaging System (LI-COR)

Apoptosis assay. siRNA-targeted and drug-treated cells were used to determine the translocation of phosphatidylserine from the inner to the outer surface of the plasma membrane during apoptosis by using the human phospholipid-binding protein, annexin V, conjugated to FITC, as according to the manufacturer's instructions (BD Biosciences). The percentage of apoptotic (annexin V-positive and propidium iodide-negative) cells was determined by flow cytometric analysis (BD Biosciences Immunocytometry Systems BD FACSDiva and De Novo FCS Express V3).

Quantitative reverse transcription-PCR. To measure relative mRNA expression levels, total RNA was isolated from cells after siRNA and drug treatments (RNeasy Mini Kit, Qiagen). One step quantitative reverse transcriptionPCR was performed using the QuantiTect SYBRGreen RT-PCR kit (Qiagen) with $100 \mathrm{ng}$ total RNA with validated gene-specific QuantiTect Primers (c-FLIP: QT00064554; GAPDH: QT01192646; $\beta$-actin: QT01680476) on an Eppendorf Mastercycler ep realplex. No genomic DNA amplification was seen with controls that lack the reverse transcription step (i.e., $>10$ cycle difference compared with complete protocol)

Statistical analysis. Statistical comparisons were performed using ANOVA with post hoc Tukey's HSD.

\section{Conflict of Interest}

RG Korneluk is a founder and shareholder of ÆEgera Therapeutics Inc., which designed SMC-AEG40730. The remaining authors declare no conflict of interest.

Acknowledgements. SMC (SM-164) was kindly provided by Dr. S Wang, University of Michigan. This work was supported by funds from the Canadian Institutes of Health Research (\#86627), The Ottawa Neuroblastoma Research Fund and The James Birrell Neuroblastoma Research Fund and joint funding from Ontario Institute for Cancer Research (OICR) and Terry Fox Research Institute. Funding for OICR is provided by the Ministry of Research and Innovation from the province of Ontario. RA Screaton holds the Canada Research Chair in Apoptotic Signalling. RG Korneluk is a Howard Hughes Medical Institute International Research Scholar, a Fellow of the Royal Society of Canada and a Distinguished Professor of the University of Ottawa.

1. Hanahan D, Weinberg RA. Hallmarks of cancer: the next generation. Cell 2011; 144 646-674.

2. Gyrd-Hansen M, Meier P. IAPs: from caspase inhibitors to modulators of NF-kappaB, inflammation and cancer. Nat Rev Cancer 2010; 10: 561-574.

3. Flygare JA, Fairbrother WJ. Small-molecule pan-IAP antagonists: a patent review. Expert Opin Ther Pat 2010; 20: 251-267.

4. Mace PD, Shirley S, Day CL. Assembling the building blocks: structure and function of inhibitor of apoptosis proteins. Cell Death Differ 2010; 17: 46-53.

5. O'Riordan MX, Bauler LD, Scott FL, Duckett CS. Inhibitor of apoptosis proteins in eukaryotic evolution and development: a model of thematic conservation. Dev Cell 2008; 15: $497-508$

6. Bertrand MJ, Milutinovic S, Dickson KM, Ho WC, Boudreault A, Durkin J et al. cIAP1 and CIAP2 facilitate cancer cell survival by functioning as E3 ligases that promote RIP1 ubiquitination. Mol Cell 2008; 30: 689-700

7. Mahoney DJ, Cheung HH, Mrad RL, Plenchette S, Simard C, Enwere E et al. Both clAP1 and clAP2 regulate TNFalpha-mediated NF-kappaB activation. Proc Natl Acad Sci USA 2008; 105: 11778-11783.

8. Varfolomeev E, Goncharov T, Fedorova AV, Dynek JN, Zobel K, Deshayes K et al. c-IAP1 and C-IAP2 are critical mediators of tumor necrosis factor alpha (TNFalpha)-induced NF-kappaB activation. J Biol Chem 2008; 283: 24295-24299.

9. Cheung HH, Mahoney DJ, Lacasse EC, Korneluk RG. Down-regulation of c-FLIP Enhances death of cancer cells by smac mimetic compound. Cancer Res 2009; 69: 7729-7738.

10. Wang $L$, Du F, Wang $X$. TNF-alpha induces two distinct caspase-8 activation pathways. Cell 2008; 133: 693-703.

11. Du C, Fang M, Li Y, Li L, Wang X. Smac, a mitochondrial protein that promotes cytochrome c-dependent caspase activation by eliminating IAP inhibition. Cell 2000; 102: 33-42. 
12. Verhagen AM, Ekert PG, Pakusch M, Silke J, Connolly LM, Reid GE et al. Identification of DIABLO, a mammalian protein that promotes apoptosis by binding to and antagonizing IAP proteins. Cell 2000; 102: 43-53.

13. Wu G, Chai J, Suber TL, Wu JW, Du C, Wang X et al. Structural basis of IAP recognition by Smac/DIABLO. Nature 2000; 408: 1008-1012.

14. Gaither A, Porter D, Yao Y, Borawski J, Yang G, Donovan J et al. A Smac mimetic rescue screen reveals roles for inhibitor of apoptosis proteins in tumor necrosis factor-alpha signaling. Cancer Res 2007; 67: 11493-11498.

15. Lu J, Bai L, Sun H, Nikolovska-Coleska Z, McEachern D, Qiu S et al. SM-164: a novel, bivalent Smac mimetic that induces apoptosis and tumor regression by concurrent removal of the blockade of CIAP-1/2 and XIAP. Cancer Res 2008; 68: 9384-9393.

16. Varfolomeev E, Blankenship JW, Wayson SM, Fedorova AV, Kayagaki N, Garg P et al. IAP antagonists induce autoubiquitination of c-IAPs, NF-kappaB activation, and TNFalphadependent apoptosis. Cell 2007; 131: 669-681.

17. Vince JE, Wong WW, Khan N, Feltham R, Chau D, Ahmed AU et al. IAP antagonists target CIAP1 to induce TNFalpha-dependent apoptosis. Cell 2007; 131: 682-693.

18. Petersen SL, Wang L, Yalcin-Chin A, Li L, Peyton M, Minna J et al. Autocrine TNFalpha signaling renders human cancer cells susceptible to Smac-mimetic-induced apoptosis. Cancer Cell 2007; 12: 445-456.

19. Wu Y, Zhou BP. TNF-alpha/NF-kappaB/Snail pathway in cancer cell migration and invasion. Br J Cancer 2010; 102: 639-644.

20. Mikus J, Steverding D. A simple colorimetric method to screen drug cytotoxicity against Leishmania using the dye Alamar Blue. Parasitol Int 2000; 48: 265-269.

21. Zhang JH, Chung TD, Oldenburg KR. A simple statistical parameter for use in evaluation and validation of high throughput screening assays. J Biomol Screen 1999; 4: 67-73.

22. Weber A, Kirejczyk Z, Besch R, Potthoff S, Leverkus M, Hacker G. Proapoptotic signalling through Toll-like receptor-3 involves TRIF-dependent activation of caspase-8 and is under the control of inhibitor of apoptosis proteins in melanoma cells. Cell Death Differ 2010; 17: 942-951.

23. Kang J, Kisenge RR, Toyoda H, Tanaka S, Bu J, Azuma E et al. Chemical sensitization and regulation of TRAIL-induced apoptosis in a panel of B-lymphocytic leukaemia cell lines. Br J Haematol 2003; 123: 921-932.

24. Ruemmele FM, Beaulieu JF, O'Connell J, Bennett MW, Seidman EG, Lentze MJ. The susceptibility to Fas-induced apoptosis in normal enterocytes is regulated on the level of cIAP1 and 2. Biochem Biophys Res Commun 2002; 290: 1308-1314.

25. Probst BL, Liu L, Ramesh V, Li L, Sun H, Minna JD et al. Smac mimetics increase cancer cell response to chemotherapeutics in a TNF-alpha-dependent manner. Cell Death Differ 2010; 17: 1645-1654.

26. Ndubaku C, Varfolomeev E, Wang L, Zobel K, Lau K, Elliott LO et al. Antagonism of c-IAP and XIAP proteins is required for efficient induction of cell death by small-molecule IAP antagonists. ACS Chem Biol 2009; 4: 557-566.

27. Chang L, Kamata H, Solinas G, Luo JL, Maeda S, Venuprasad K et al. The E3 ubiquitin ligase itch couples JNK activation to TNFalpha-induced cell death by inducing c-FLIP(L) turnover. Cell 2006; 124: 601-613.
28. Dejardin E. The alternative NF-kappaB pathway from biochemistry to biology: pitfalls and promises for future drug development. Biochem Pharmacol 2006; 72: 1161-1179.

29. Zarnegar B, Yamazaki S, He JQ, Cheng G. Control of canonical NF-kappaB activation through the NIK-IKK complex pathway. Proc Natl Acad Sci USA 2008; 105 3503-3508.

30. Micheau O, Lens S, Gaide O, Alevizopoulos K, Tschopp J. NF-kappaB signals induce the expression of c-FLIP. Mol Cell Biol 2001; 21: 5299-5305.

31. Shirley S, Micheau O. Targeting c-FLIP in cancer. Cancer Lett, e-pub ahead of print 9 November 2010

32. Zarnegar BJ, Wang Y, Mahoney DJ, Dempsey PW, Cheung HH, He J et al. Noncanonical NF-kappaB activation requires coordinated assembly of a regulatory complex of the adaptors CIAP1, cIAP2, TRAF2 and TRAF3 and the kinase NIK. Nat Immunol 2008; 9: $1371-1378$.

33. Irmler M, Thome M, Hahne M, Schneider P, Hofmann K, Steiner V et al. Inhibition of death receptor signals by cellular FLIP. Nature 1997; 388: 190-195.

34. Micheau O, Tschopp J. Induction of TNF receptor I-mediated apoptosis via two sequential signaling complexes. Cell 2003; 114: 181-190.

35. Gehen SC, Staversky RJ, Bambara RA, Keng PC, O'Reilly MA. hSMG-1 and ATM sequentially and independently regulate the $\mathrm{G} 1$ checkpoint during oxidative stress. Oncogene 2008; 27: 4065-4074.

36. Chen RQ, Yang QK, Chen YL, Oliveira VA, Dalton WS, Fearns $C$ et al. Kinome siRNA screen identifies SMG-1 as a negative regulator of hypoxia-inducible factor-1alpha in hypoxia. J Biol Chem 2009; 284: 16752-16758.

37. Oliveira V, Romanow WJ, Geisen C, Otterness DM, Mercurio F, Wang HG et al. A protective role for the human SMG-1 kinase against tumor necrosis factor-alpha-induced apoptosis. J Biol Chem 2008; 283: 13174-13184.

38. Yamashita A, Ohnishi T, Kashima I, Taya Y, Ohno S. Human SMG-1, a novel phosphatidylinositol 3-kinase-related protein kinase, associates with components of the mRNA surveillance complex and is involved in the regulation of nonsense-mediated mRNA decay. Genes Dev 2001; 15: 2215-2228.

39. Gallagher E, Gao M, Liu YC, Karin M. Activation of the E3 ubiquitin ligase Itch through a phosphorylation-induced conformational change. Proc Natl Acad Sci USA 2006; 103: 1717-1722.

40. Wilson TR, McEwan M, McLaughlin K, Le Clorennec C, Allen WL, Fennell DA et al. Combined inhibition of FLIP and XIAP induces Bax-independent apoptosis in type II colorectal cancer cells. Oncogene 2009; 28: 63-72.

Cell Death and Disease is an open-access journal published by Nature Publishing Group. This work is licensed under the Creative Commons Attribution-Noncommercial-No Derivative Works 3.0 Unported License. To view a copy of this license, visit http://creativecommons.org/licenses/by-nc-nd/3.0/

\section{Supplementary Information accompanies the paper on Cell Death and Disease website (http://www.nature.com/cddis)}

